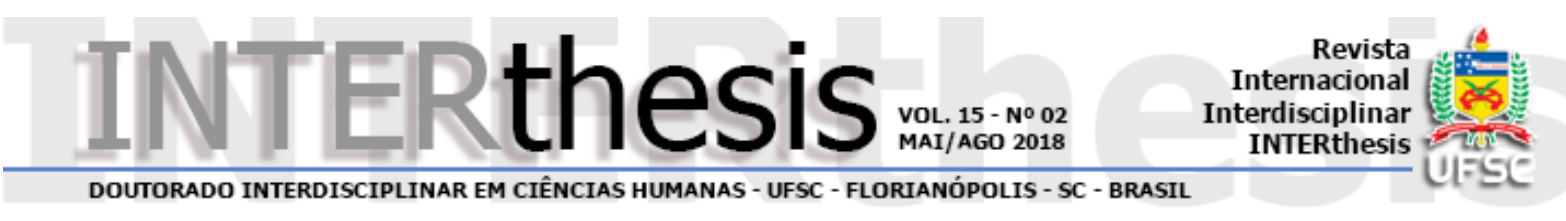

\title{
INSEGURANÇAS, INCERTEZAS E O DESALENTO PÓS-MODERNO: O ESTADO DE CRISE NOS ÚLTIMOS TEXTOS DE ZYGMUNT BAUMAN
}

\section{Resumo:}

Rodolfo Rodrigo Santos Feitosa ${ }^{1}$

A realidade social contemporânea é marcadamente associada a circunstâncias que geram um "permanente estado de crise". Zygmunt Bauman se destacou pela atenção dedicada à compreensão do status de crise na modernidade líquida. O presente ensaio lança luz sobre duas de suas últimas obras, a saber, Estado de Crise e Estranhos à nossa porta. Os argumentos e ideias destacados à discussão representam possibilidades a abordagens interdisciplinares que interpelem a condição humana e as práticas sociais hodiernas. Neste sentido, a perda do poder de agência do Estado, a difusão dos riscos e vulnerabilidades decorrentes, assim como as condutas de estranhamento e desconfiança à alteridade, são questões debatidas à luz de outras obras do autor e em diálogo com contribuições recentes da teoria social. A reflexão aponta o caráter indissolúvel da crise na pós-modernidade como fonte de tensão que articula incertezas, inseguranças e vulnerabilidades, asseverando o individualismo e a hostilidade em determinados contextos, sendo a autocrítica social um caminho viável para se evitar esses problemas.

Palavras-chave: Estado. Democracia. Migração. Globalização.

\section{INTRODUÇÃO}

Entre os elementos que caracterizam a sociedade contemporânea, sua "condição de instabilidade" é algo marcadamente difícil de ser ignorado. É razoável afirmar que um diagnóstico de tal condição dificilmente seja elaborado tomando como base um único vetor causal. Mesmo o fenômeno da globalização, frequentemente articulado ao apanágio da volatilidade na história social recente, é inviável como recurso explicativo isolado. Não por acaso, os aspectos e sentimentos sociais, direta e indiretamente relacionados à dificuldade de se estabelecer constâncias ordeiras na sociedade contemporânea, têm desafiado os analistas desde os anos 1970 (HELD; MCGREW, 2001). Neste sentido, sobressaem as interpelações acerca das transformações nos comportamentos sociais e as consequências decorrentes para as

\footnotetext{
${ }^{1}$ Doutor em Sociologia pela Universidade Federal de Pernambuco. Professor do Instituto Federal de Educação, Ciência e Tecnologia do Sertão Pernambucano em Petrolina, PE, Brasil E-mail: rrfeitosa@gmail.com
} 
sociabilidades e os modos de vida cotidianos.

Ao debruçar-se analiticamente sobre essa particular "condição instável" vivenciada pela sociedade atual (sujeitos, instituições e relações), Zygmunt Bauman construiu um legado teórico de grande importância não apenas à sociologia, mas ao vasto campo das ciências humanas. Em seus escritos, o recurso à construção de diálogos com variados pensadores e pensamentos mostrou-se instrumento de elucidação de uma realidade deveras complexa, detentora de seu próprio "mal-estar" e única na série de incertezas que compila (BAUMAN, 1998). A "condição de crise" pós-moderna é ampla, ao abarcar estruturas, indivíduos e valores promove não apenas alterações severas nas instituições e práticas sociais, mas acaba reconfigurando ideais e utopias de sociedade, isto é, as nossas próprias projeções de futuro para a humanidade.

O horizonte de crise sem fim tem vínculos diretos com as agitações deixadas pela passagem da embarcação da modernidade, embora não se resuma a uma simples decorrência dos inconclusos programas desse momento anterior. Lembremos que, "mais do que tudo, os projetos modernos de perfeição global tiraram seu ímpeto do horror à diferença e da impaciência com a alteridade" (BAUMAN, 1999, p. 272), sendo eles mesmos responsáveis pelo efeito paradoxal de difusão de diferenças e a decorrente fragmentação social. Toda a ambivalência gestada na era moderna não se esvai na pós-modernidade, ao contrário, se estabelece reconhecida em suas características e nas problemáticas que Ihes circundam, muitas das quais promotoras dos vazios dos sujeitos de nosso tempo e de suas identidades indeterminadas. No horizonte da liquidez, "[...] as identidades talvez sejam as encarnações mais aguçadas, mais profundamente sentidas e perturbadoras da ambivalência" (BAUMAN, 2005, p. 38, grifo do autor).

O arrojo moderno pela classificação e pela ordem deixaram marcas entranhadas, especialmente pelas violências e submissões que foram designadas em seu nome. Ao mesmo tempo, herdamos lacunas e cisões pertinentes aos processos de integração social que, eivados por sensações de insegurança e abandono, compõem parte considerável das nossas percepções sobre a alteridade e o modo como lidar com elas, sobretudo diante das incertezas que se avolumam. Consciente ou inconscientemente, as ações no cotidiano revelam os sentimentos predominantes acerca da alteridade, bem como expressam nossa visão aturdida frente a questões para as quais não dispomos de instrumentos resolutivos, mas que recaíram como 
nossa atribuição na versão contemporânea do pacto social. Neste sentido, na pósmodernidade as relações sociais tanto podem refletir uma busca pela comunidade $\mathrm{e}$ os laços integradores por ela propiciados (BAUMAN, 2003), quanto podem expressar a repulsa e a intolerância à alteridade, revelando, por sua vez, a fragilidade dos sonhos gregários universalistas.

Duas das últimas obras de Bauman publicadas no Brasil ressaltam importantes elementos para reflexão e análise da permanente turbulência pós-moderna. Estado de crise ${ }^{2}$ e Estranhos à nossa porta são títulos que, inevitavelmente, nos colocam diante de conceitos e ideias trabalhadas pelo autor em outros momentos, mas que também possibilitam novos olhares sobre a conformação das conjunturas sociais dos dias de hoje. Merece menção o fato de que os citados textos elaboram uma articulação didática de ideias que, no conjunto da obra do autor, ocuparam uma discussão mais densa em vários títulos. Por esse caráter e pela apropriação de fatos históricos recentes e instigantes ao leitor, esses textos tendem a uma rápida popularização, de modo que as nossas ponderações podem contribuir para uma melhor apreensão dos argumentos ali desenvolvidos, partindo de uma base compreensiva que suscita tanto usos analíticos quanto vínculos teórico-conceituais possíveis com obras do próprio autor e de outros intelectuais.

Sendo assim, este ensaio busca abordar as principais noções teóricas e os raciocínios analíticos que as envolvem, a fim de destacar os incrementos que tais títulos permitem aos estudiosos dedicados à compreensão da condição humana em contextos atuais. Localizamos a importância desses debates no conjunto da obra baumaniana, dando centralidade às questões em torno da condição pós-moderna em a crise não se estabelece como episódio fortuito, bem como suas implicações para as relações sociais e padrões de sociabilidade. Sob este desenho, incorporamos à reflexão outros nomes importantes da teoria social, os quais também despenderam atenção à investigação desse traço de incerteza peculiarmente sobressalente em nossos dias, favorecendo insights sobre a conformação notoriamente atordoante da condição de crise na contemporaneidade.

\footnotetext{
${ }^{2}$ Quanto à participação de Carlo Bordoni no texto, este ensaio guardou as devidas ressalvas quando se fizeram necessárias à distinção de entendimento em relação a Bauman.
} 


\section{PROCEDIMENTOS OPERACIONAIS}

O caráter ensaístico do presente texto permitiu um percurso analítico mais fluido, de modo que o expediente operacional adotado orientou-se basicamente pelo bom alinhavado das ideias. Assim, optamos por um encadeamento que possibilitasse entender o teor dessas recentes contribuições de Bauman e o incremento que promovem ou suscitam à análise da realidade social. Para tanto, não dispensamos os apontamentos voltados à conexão dos elementos teóricos que perfazem a trajetória de construção das principais ideias do autor e que voltam à tona de maneira singularmente didática nas obras destacadas.

Inicialmente, o ensaio pontua os principais approaches contidos em Estado de Crise refletidos à luz do arcabouço teórico geral da modernidade líquida e seus atributos mais incisivos (BAUMAN, 2001). Os elementos dessa incursão serviram de prelúdio para o debate subsequente acerca da instabilidade democrática atual e da emergência de dilemas de amplo impacto na conformação social. As percepções daí oriundas serviram como suporte para análise dos impasses especificamente atrelados aos surtos migratórios recentes. Neste momento, a reflexão abarca os argumentos trazidos pelo título Estranhos à nossa porta, cuja problemática evidencia bem a natureza de certas questões de ordem política, econômica, cultural e também moral tão caras à nossa realidade. Para a reflexão dos elementos de cada obra a estruturação do ensaio compreende um segmento específico, no qual ganham espaço algumas das conexões possíveis com a teoria geral e outras chaves de pensamento do autor, sobretudo os fundamentos mais emblemáticos para uma possível utilização com vistas à reflexão da conjunção atual quanto ao seu caráter inalienável de instabilidade permanente.

Reconhecemos que as referidas obras permitem desdobramentos de natureza interdisciplinar, uma vez que tencionam aspectos fundamentais à condição humana e social na modernidade líquida. Esta, por sua vez, apresenta-se inevitavelmente equacionada à circunstância da partilha global dos problemas, constituindo uma sensação etérea de medo e incerteza, revertida e materializada em condições e reações efusivas, as quais perpassam pelas dúvidas da identidade e da composição gregária (BAUMAN, 2003, 2005). À revelia da promessa moderna na constituição das instituições de regulação e ordenamento, "nossa vida está longe de ser livre do medo, e o ambiente líquido-moderno em que tende a ser conduzida está longe de ser livre 
de perigos e ameaças" (BAUMAN, 2008, p. 15). No que tange às "adversidades" como o terrorismo e os choques interculturais, a globalização, pontualmente em seu viés negativo, deu força ao "espectro da vulnerabilidade", passando o perigo a ser condição comum a todos os indivíduos, ao mesmo tempo em que sobre todos eles recai o véu da suspeição (BAUMAN, 2008, p. 128). Não à toa, medo, instabilidade, fragmentação e crise fazem parte do repertório analítico que Bauman retoma em Estado de Crise e Estranhos à nossa porta, ratificando sua importância no entendimento dos fenômenos correntes do século XXI e, por isso mesmo, merecem especial atenção de nossa parte.

Utilizamos dois movimentos para destacar, a partir de tais obras, os elementos cogentes que o autor propõe ao exame das interações sociais, a saber, o destaque para percursos reflexivos voltados ao entendimento de fenômenos específicos ou o grifo de determinadas chaves conceituais que se apresentem relevantes à apreensão da realidade atual no que toca à temática enfatizada. Desta forma, os recortes sobressaltados são apenas alguns dos tantos possíveis, e se fizeram conforme predisposições interpretativas conjuminadas com outros aportes analíticos que seguem acionados alinhavando os argumentos apresentados no ensaio.

\section{A CRISE DE PODER DO ESTADO E A DESVIRTUOSA CONDIÇÃO CONTEMPORÂNEA}

Não é de hoje que a sociedade convive com um sentimento estranho de permanente turbulência. Em verdade, essa condição consta presente no horizonte analítico de diversos pensadores, assumindo tons e explicações variadas. A difusão global (quase irrestrita) dessa realidade convulsiva reflete, para alguns, uma conjuntura histórica suscitada pelo enfraquecimento de instituições sociais e políticas estruturalmente arcaicas, em torno das quais se trava o conflito por novos e velhos espaços de poder, sinalizando, assim, a emergência de um novo sistema social (TOFFLER, 2001). Neste caso, a instabilidade das transformações econômicas, políticas e culturais não seriam meras ocorrências episódicas e destituídas de um sentido comum, mas sim um movimento encadeado a certa matriz sistêmica típica de cada grande momento histórico, representado, neste instante, pela civilização pósindustrial.

Por outro lado, pensadores como Beck (2010) e Giddens (1991) dão ênfase à grandiosidade dos riscos que circundam nossa situação existencial hoje, assim como 
à previsão futura de um arcabouço social no qual a distribuição de riscos se tornará condição decisiva na conformação dos conflitos sociais, muito mais que a própria redistribuição de riquezas. $O$ aumento quantitativo e a elevação exponencial do poder de destruição desses riscos, (regionais e locais em origem, mas globais em impacto e amplitude) acabam por promover alterações decisivas nas formas de sociabilidade, "[...] em tal medida que a imaginação humana fica desconcertada diante delas" (BECK, 2010, p. 25).

Em face da torrente de riscos e medos, uma inquietude proveniente da potencialização da vulnerabilidade finca raízes na modernidade líquida, afetando notoriamente as instituições e os sujeitos, impelindo-os a condutas que, em muitos casos, contrariam os supostos alicerces "morais" que fundamentaram a civilização ocidental, especialmente aquela desenhada na "aventura" chamada Europa (BAUMAN, 2006). De modo simplificativo, poderíamos dizer que nos seus escritos recentes o autor leva em consideração os efeitos mais práticos repercutidos por instituições e indivíduos quanto aos sentimentos e sensações derivados da condição permanente de crise e da vulnerabilidade a ela atrelada. É sobre este tipo de enredo que suas investidas analíticas fogem ao escopo exclusivo da sociologia, constituindose como recurso igualmente proveitoso às abordagens interdisciplinares direcionadas a esse tipo de problemática emergente.

Sem prescindir de evidências históricas para o entendimento das notavelmente instáveis conjunturas políticas e econômicas atuais, Bauman e Bordoni (2016) intencionam esclarecer alguns dos porquês relativos ao estado de crise e à crise do Estado. Neste caso, abordam tanto a circunstância condicional em que vivemos, na qual as crises são indissolúveis e difusas, existindo, por assim dizer, como uma espécie de componente inexpugnável da realidade hodierna; como lançam olhares acerca do colapso do Estado-Nação, cujo poder que Ihe concedia capacidade resolutiva foi açambarcado por outras instâncias econômicas e supraestatais.

A conexão entre as incontáveis crises político-econômicas e a falência do Estado-nação se apresenta indiscutível no cenário presente. As reincidentes turbulências que afetam os países prosperam justamente por faltar ao Estado faculdades e insumos resolutivos, sendo tal insuficiência resolutiva marca decisiva do "divórcio entre poder e política" promovido pela apartação da esfera econômica em relação aos marcos regulatórios e limitadores (BAUMAN; BORDONI, 2016, p. 22). O domínio do capital móvel e o fortalecimento das instâncias decisórias supraestatais 
como os espaços privilegiados de definição e de poder são movimentos que mitigam a soberania territorial do Estado. O declínio da potência de ação que atinge o Estado não é uma constatação propriamente nova, mas, para ambos, parece assumir agora feições ainda mais dramáticas, sobretudo por conta da ampliação da experiência de abandono dos indivíduos à própria sorte. Além disso, o mercado, o capital e todas as demais forças supraestatais que operam no chamado "espaço de fluxos" (CASTELLS, 1999) desataram quase que completamente as amarras territoriais e normativas à figura do Estado. Pelo expediente das novas formas administrativas e operacionais globalizadas as instâncias de operação livre se multiplicam e se valorizam, criando uma dinâmica por meio da qual regem suas próprias regulações. Neste sentido, despojado de seu poder efetivo de resolução, o Estado carece da capacidade de agência que o tornava "respeitável" e matinha os cidadãos crédulos à solução de determinadas demandas, pelo menos em tempos de apuros.

Conforma-se, então, um estatismo sem Estado3 ${ }^{3}$, ao qual se associa a "crise de agência" (BAUMAN; BORDONI, 2016, p. 34). Esta, por sua vez, sinaliza uma emblemática dificuldade do Estado em lidar com problemas de natureza global que se fazem concretos no território de exercício de sua soberania. Em outras palavras, os poderes resolutivos (se é que existem) para problemas econômicos de ordem global estão concentrados sob a posse de agentes supraestatais. Stiglitz (2002) atesta a condição de exiguidade de meios do Estado no que tange ao enfrentamento de questões dessa ordem, enfatizando o Fundo Monetário Internacional e o Banco Mundial como as instituições supraestatais com poder suficiente (até certo ponto) para a dissolução de certos imbróglios nessa esfera. Todavia, a atuação de tais instituições, bastante questionável por sinal, tem favorecido muito mais a criação de novos abismos do que a solução dos problemas existentes. Uma observação retrospectiva das ações desses poderosos agentes internacionais demonstra que, não raramente, à revelia do que pretendido (supostamente), "o resultado para muitas pessoas tem sido a pobreza, e para muitos países o caos político e social" (STIGLITZ, 2002, p.45).

Mais do que nunca, "o Estado não dispõe dos meios e recursos para realizar as tarefas que exigem a supervisão e o controle efetivos dos mercados, para não falar de sua regulação e administração" (BAUMAN; BORDONI, 2016, p. 21). Uma situação que acarreta severa perda de credibilidade por parte dos cidadãos, especialmente

\footnotetext{
${ }^{3}$ Ideia que os autores tomam por empréstimo do filósofo francês Étienne Balibar.
} 
quando reconhecem que o minguado interesse coletivo, ainda que faça parte da agenda do Estado, não consegue confrontar os desejos do mercado. Inviável financeiramente e reprovável no modelo neoliberal, a atenção do Estado para com os indivíduos sob sua tutela é reduzida a um esquema mínimo. O interessante é que o quadro do esquema mínimo se radicaliza em meio às conturbações duradouras e, paradoxalmente, justamente no momento em que os indivíduos requisitam algum grau de amparo por parte do Estado acabam desassistidos, relegados à própria sorte. Sobre o pressuposto da racionalidade neoliberal operam hegemônicos os princípios estimuladores do individualismo, coadunados com o modelo de gestão administrativa assumido pelo Estado.

O Estado lava as mãos quanto à vulnerabilidade e a incerteza provenientes da lógica (da falta de lógica) do livre mercado. A deletéria fragilidade da condição social é redefinida como assunto privado - uma questão com que os indivíduos devem lidar e se confrontar usando seus próprios recursos (BAUMAN; DONSKIS, 2014, p. 130).

Esse tipo de conformação parece, cada vez mais, distar dos interesses de grandes camadas da população e assume delineamentos preocupantes nos países do Terceiro Mundo, sobretudo porque a fatia populacional em condição de vulnerabilidade dilata-se facilmente e é bem mais significativa do que nos países abastados. Segundo Shiva (2004, p. 164), o panorama se consolida também pelo modus operandi de agentes supraestatais ${ }^{4}$ que "estão impondo à natureza, às mulheres e ao Terceiro Mundo o custo do ajuste" entre produção econômica e impactos socioambientais. Na prática, o modelo econômico global de hoje significa não apenas a multiplicação de riscos, mas especialmente sua concentração e privatização. Como indicaram Faux e Mishel (2004, p. 161), "no mar tempestuoso da competição econômica global, onde só os investidores da primeira classe recebem coletes salva-vidas", o número de desesperados a se debater na água em busca da sobrevivência é cada vez mais numeroso.

É de se imaginar que em uma circunstância tão cruel e assustadora alguns pilares ideológicos do Estado (e da própria modernidade) sejam duramente interrogados, se já não constarem completamente desacreditados. Neste sentido, a questão se torna mais profunda e a condição de crise ultrapassa, e muito, a simples falência estatal. A este respeito, Bauman e Bordoni (2016) discutem o quanto da

\footnotetext{
${ }^{4}$ A exemplo do Banco Mundial, do Fundo Monetário Internacional e da Organização Mundial do Comércio.
} 
instabilidade de hoje deriva dos processos de ruptura atrelados ao não cumprimento das principais promessas/estratégias ${ }^{5}$ da modernidade. A democracia certamente é um desses pilares modernos estratégicos que não conseguiu escapar da tormenta, e toda sorte de interpelações aplicáveis à sua forma atual referendam a dúvida sobre a efetividade de suas realizações. Individualismo e consumismo são ideais do paradigma econômico dominante e refletem a racionalidade de uma esfera da sociabilidade humana muito particular. Quando são transmitidos como propósitos a serem perseguidos pela sociedade, acabam por se configurar como malogros que trazem em seu revés mais incertezas aos indivíduos (BAUMAN, 2001).

Essas incertezas, adidas do declínio da confiança no poder resolutivo do Estado, destacam fendas na forma como a democracia vem se constituindo, e podemos senti-las especialmente na tensão entre suprema liberdade e mínima segurança. $O$ fracasso no provimento adequado de interesses partilhados coletivamente assevera a descrença na política e deixa margem para comportamentos que personificam essas fendas como a ascendente apatia política captada pela ideia de "pós-democracia" ( $\mathrm{CROUCH}, 2004)$. Porém, pelo caminhar das coisas na fase líquida da modernidade não era difícil vislumbrar o esgotamento do Estado em sua versão compromissada e protetora, nem tampouco o desestímulo com a política, uma vez que o acalento da integração social há muito se deslocou para a esfera do mercado, e este é espaço de realização privativa. Todo esse processo, retratado por Bauman e Bordoni (2016) em que o cidadão se afasta da política reflete, na verdade, um tipo particular de prática adotada pelo sucessor do "Estado moderno", a qual se baseia "no expediente de privatizar a dissensão e torna-la difusa, em vez de coletivizá-la e instigá-la a se acumular" (BAUMAN, 1999, p. 197).

Em tal cenário, o desalento que se abate sobre os indivíduos é inevitável. Atomizados em suas incumbências de resolução de problemas que não criou, os indivíduos atestam, dia após dia, que suas chances de êxito são minguadas. Em linhas gerais, há muito pouco de permanência nos laços que se estabelecem e a dinâmica condição da pós-modernidade aos estabelecer o frívolo e o instantâneo como lógicas predominantes, afastam a possibilidade de êxito das construções coletivas de médio

\footnotetext{
${ }^{5} \mathrm{Na}$ obra em questão os argumentos não são homogêneos, pois, a este respeito, Bauman reluta em aceitar que "promessas" da modernidade foram renunciadas, motivo pelo qual compreende inadequado o termo utilizado por Bordoni, preferindo denominá-las como "estratégias" e "ilusões" de uma fase juvenil da modernidade.
} 
e longo prazo, como é o caso da política. De um modo ou de outro, essa discussão permeia uma parcela expressiva da produção teórica da sociologia dos últimos trinta anos, estando presente em várias manifestações teórico-conceituais.

Os teóricos franceses falam de précarité, os alemães de Unsicher/zeit e Risikogesellschaf, os italianos de incerlezza e os ingleses, de insecurity - mas todos têm em mente o mesmo aspecto da condição humana, experimentada de várias formas e sob nomes diferentes por todo o globo [...] O fenômeno que todos esses conceitos tentam captar e articular é a experiência combinada da falta de garantias (de posição, títulos e sobrevivência), da incerteza (em relação à sua continuação e estabilidade futura) e de insegurança (do corpo, do eu e de suas extensões: posses, vizinhança, comunidade) (BAUMAN, 2001, p. 185, grifo do autor).

O caráter que sentimentos como "vazio existencial", "vulnerabilidade", "insegurança" e "instabilidade" adquirem no tecido social é decisivo na conformação das relações entre os sujeitos e entre estes e as instituições, ou seja, constituem parte da configuração geral das sociedades modernas. Para Giddens (2010), tal arranjo ratifica a significância dos riscos na determinação de transformações cruciais no modo como nós (re)avaliamos ações e relações e instituímos padrões de confiança e segurança. Em verdade, "esses riscos, e os dilemas que os envolvem, penetram profundamente em nossas vidas cotidianas" (GIDDENS, 2010, p. 43). Da questão ambiental ao terrorismo, aprendemos a conviver com os riscos e a partir deles instituímos novas versões de organização do poder e responsabilidade (BECK, 2010).

Contudo, os riscos e as vulnerabilidades que se articulam nos dias de hoje apresentam dilemas pertinentes à própria condição de integração social, não apenas porque questionam o ordenamento das motivações legitimadoras do Estado como agente supostamente incumbido pela proteção social, mas especialmente pelo fato de despertarem uma espécie "estágio mental de desconfiança permanente" em relação aos "outros". Esses "estranhos" acabam materializando os perigos à nossa existência, na grande maioria das vezes por meio de discursos e situações que muito pouco de verdade possuem, mas que atingem diretamente a opinião popular e difundem as impressões necessárias à justificação da suspensão da moral na resolução, por exemplo, do "problema da migração". Nessa nova conjuntura as relações com os migrantes (reconhecidamente estranhos e potencialmente hostis) tendem a ser conduzidas predominantemente por formas que se afinam com governos e chefes políticos de tonalidades belicosas. As possibilidades não agradáveis daí decorrentes foram observadas por Bauman (2017) e constituem mais uma das faces da turbulenta circunstância social da pós-modernidade. 


\section{4 “CRISE MIGRATÓRIA": DA VULNERABILIDADE À HOSTILIDADE}

A "questão migratória" recente soa um pouco diferente de outras circunstâncias em que o deslocamento humano em massa foi registrado ao longo da história. A situação atual parece ensejar articulações que atribuem às temáticas pertinentes aos contingentes populacionais migrantes um cuidado especial, não por acaso, muitos países têm constituído agendas políticas específicas para tais fins. Certamente uma condição não generalizável a todas as ocasiões, mas que tem se destacado que no que se refere aos fluxos com destino à Europa que nos últimos se intensificaram.

De acordo com Giddens (2014), a Europa como um todo vivencia uma conjuntura econômica não muito favorável. Das medidas de austeridade às tentativas de reestabelecer normalidade para taxas de desemprego, pouco avanço parece ter sido feito pelos países, especialmente porque as estratégias voltadas ao crescimento dos grandes setores que movimentam o mercado de trabalho surtem cada vez menos efeito, uma vez que a hipermobilidade do capital e a flexibilização da mão de obra suscitam oportunidades mais vantajosos em outras partes do planeta.

Para além da perspectiva macroeconômica, uma análise a partir do lugar dos indivíduos sugere uma realidade ainda mais dura, pois se soma ao cenário geral de o revés do declínio das políticas sociais e as reformas trabalhistas que, grosso modo, asseveraram o quadro de insegurança e precariedade quanto à condição de emprego. Esse panorama faz parte dos elementos contextuais necessários ao entendimento daquilo que está por trás da escalada dos referidos fluxos migratórios à categoria de "crise", o que implica em um tratamento peculiar da questão de modo por parte das lideranças governamentais europeias.

As incapacidades do Estado em "defender" os indivíduos frente aos dissabores do mercado, como discutido no tópico anterior, já são mais que aparentes e reconhecidas há tempos, tendo suscitado seu descrédito e a própria fragmentação da capacidade de agência para a grande maioria das questões dessa natureza (BAUMAN; BORDONI, 2016). Na conformação social atual, os medos e perigos difusamente difundidos cumprem propósitos específicos, possuindo íntima ligação com a tentativa de estabelecer uma nova ordem de vulnerabilidades e incertezas que legitimem a existência e o exercício de poder do Estado contemporâneo, sobretudo no que pesa a pauta da segurança interna. Sob essa configuração a ampliação da 
sensação de perigo e o alarme à intensidade dos riscos contribuem para o sentimento geral de insegurança e funcionam como ferramentas para a radicalização da desconfiança mútua. Esta, por sua vez, favorece e justifica o conjunto de ações estatais conduzidas com dureza e austeridade para a mitigação dos perigos e (perigos) vindos de fora.

A sensação generalizada de desconfiança mútua, "talvez o efeito mais pernicioso, seminal e prolongado da obsessão com segurança" impele-nos diretamente a um "estranhamento" radical dos estrangeiros e, por conseguinte a cisões que dificultam convívio social minimamente harmonioso com a alteridade (BAUMAN; DONSKIS, 2014, p. 127). Distanciando-se dos discursos hegemônicos que induzem à naturalidade desse tipo de comportamento por parte de Estados e populações “invadidas”, Bauman (2017) debate as raízes sociais de comportamentos e práticas hostis à alteridade. Corriqueiramente a camuflagem político-midiática ora atribui o véu do terrorismo, subsequentemente justificando a "suspeição" desses migrantes, ora reproduz o argumento dos prejuízos econômicos (maior competição no mercado de trabalho e elevação dos gastos públicos com políticas assistenciais) que esses "indesejados" podem trazer aos países. Em uma ou outra dessas versões o que se alimenta indiretamente é a hostilidade, a recusa, o acirramento e outros sentimentos sociais que negam o diálogo e estimulam a escalada de posturas políticas radicais.

Isso ajuda muito a explicar a coincidência da recente migração em massa com o crescente sucesso da xenofobia, do racismo, e da variedade chauvinista de nacionalismo; e o sucesso eleitoral, ao mesmo tempo espantoso e inédito, de partidos e movimentos xenofóbicos, racistas e chauvinistas, e de seus belicosos líderes (BAUMAN, 2017, p. 18).

É preciso frisar que esse tipo de política, o qual se fortalece com a "securitização" da crise migratória ${ }^{6}$, não se torna expressivo e dominante (em muitas situações) ao acaso. A emergência de líderes e discursos cada vez mais enfáticos quanto à necessidade de endurecer as políticas de Estado pertinentes aos migrantes e refugiados encontra respaldo na aceitação popular. Embora varie de país para país quanto a essa aceitação, o fato é que tem sido evidente o crescimento do contingente favorável a esse tipo de posicionamento. Para Bauman (2017), o cenário que se desenha é particularmente propício à autorreflexão da sociedade, devendo esta

\footnotetext{
${ }^{6}$ A própria argumentação de Bauman $(2017$, p. 34$)$ nos leva a entender que alçar a questão dos fluxos de refugiados ao patamar de "crise migratória" já é, por assim dizer, uma estratégia da política de "securitização".
} 
perpassar inclusive por aspectos de natureza moral. Neste caso, na há como dissociar o tipo de tratamento que estamos permitindo, e até mesmo exigindo, que o Estado assuma para com a questão dos migrantes, de um julgamento moral que concebe a esses "estranhos" um tratamento humano diferenciado.

Tanto os próprios cidadãos europeus excluídos e alijados da distribuição de riquezas, contingente populacional crescente em países como Grécia, Portugal, Itália, Espanha e França, como o emergente precariado alargam a camada social que se conforta psicologicamente ao identificar nos migrantes refugiados uma condição de existência inferior àquela em que se encontram. "Os migrantes representam aquele fundo desejado que se situa mais abaixo ainda - abaixo do fundo a que os misérables nativos foram delegados e relegados" (BAUMAN, 2017, p. 19, grifo do autor). Esses suspeitos e indesejáveis estranhos, de origens e projetos desconhecidos, além de proporcionar o conforto à autoestima daqueles que os repudiam, materializam-se como alvo de sentimentos raivosos (ressentimentos) que acumulam toda indignação quanto às consequências maléficas da globalização.

\begin{abstract}
As "vítimas colaterais" dessas forças tendem a ser percebidas, por uma lógica viciada, como suas tropas de vanguarda, que estabelecem guarnições em nosso meio. Esses nômades - não por escolha, mas por veredicto de um destino cruel - nos lembram, de modo irritante, exasperante e aterrador, a (incurável?) vulnerabilidade de nossa própria posição e a endêmica fragilidade de nosso bem-estar arduamente conquistado (BAUMAN, 2017, p. 21).
\end{abstract}

Para o autor, fica claro, portanto, que a chamada "crise migratória" tem se constituído como um capítulo marcante da história recente, o qual tem fortes elementos dramáticos não apenas pelas imagens chocantes que produz, mas, acima de tudo, pela inevitável associação que lhe cabe quanto à dubiedade de nossa moral no tratamento com esses seres humanos que buscam alento em nossos territórios. Do mesmo, repercute negativamente nessa realidade a ascensão (no mínimo preocupante) de discursos e ações belicosas que, apoiados pela opinião popular, encontra justificada a necessidade de tratamento diferenciado para essa categoria de pessoas (BAUMAN; DONSKIS, 2014).

No geral, esse tipo de postura, o qual nutre fartos discursos xenofóbicos que vêm à tona polidos retoricamente com o verniz brilhante do nacionalismo austero, é particularmente preocupante, pois tende a ameaçar princípios que estruturam regimes políticos alinhados com a justiça e com o reconhecimento de direitos humanos invioláveis. Ao mesmo tempo, pode potencialmente revelar a extensão de mais uma 
das crises endêmicas à pós-modernidade, uma de natureza eminentemente "moral" que se alimenta da distorção dos sentidos, da fuga da realidade, da opção por soluções instantâneas e da já indicada descrença na democracia.

\section{CONSIDERAÇÕES FINAIS}

O presente ensaio refletiu alguns dos insights analíticos possibilitados por Bauman e Bordoni (2016) e Bauman (2017) ao discutirem aspectos fundamentais da realidade social contemporânea. A condição de crise indissolúvel que caracteriza a pós-modernidade é uma questão propícia a investidas interdisciplinares no campo das ciências humanas. Fator significativo de tal condição, a incapacidade resolutiva do Estado para com os problemas derivados da ordem econômica global afetam diretamente a condição de vida da maior parte dos indivíduos, ensejando um descrédito generalizado da instituição e da política. Destituído do "poder de agência" e exercendo apenas parcialmente a soberania territorial, o Estado débil contribuiu para a própria crise do regime democrático participativo, a qual pôs em xeque a realização de seus propósitos, bem como a incongruência dos meios utilizados em sua persecução. Tanto a crise do Estado quanto a da democracia estão inextricavelmente atreladas às ambivalências da modernidade (BAUMAN, 2001).

Ao tomamos em perspectiva Estado de Crise e Estranhos à nossa porta, é expressivo o reforço a ideias já trabalhadas em outras obras que lastreiam a percepção de Bauman sobre a modernidade líquida e seu estado de crise permanente. Com efeito, tanto a retomada de certos argumentos, conduzidas com compactação e didatismo, como a referência histórica de eventos recentes, podem ensejar uma utilização mais prática na compreensão da realidade atual e no estudo do pensamento baumaniano.

Mas, para além das continuidades já esperadas, alguns deslocamentos se apresentam interessantes, dentre os quais, dois merecem destaque: o primeiro diz respeito ao fato de que a análise de Bauman e Bordoni (2016) acerca do futuro político e da participação social na deliberação de questões coletivas carrega um ceticismo amadurecido e certo tom pessimista, o qual, bem pesado e bem medido, parece se distanciar das "oportunidades" vislumbradas pelo amadurecimento da modernidade quanto a uma possível revisão crítica de suas estratégias como, vez ou outra, aparece em Modernidade e Ambivalência; o segundo, por sua vez, reporta-se ao modo como 
as ponderações de Bauman (2017) sobre as práticas sociais e políticas para com a "questão migratória" articulam a intangibilidade de uma "comunidade no mundo de indivíduos" (BAUMAN, 2003, p. 134) à permanência da lógica de produção de "lixo humano" (BAUMAN, 2006, p. 103).

Por fim, é oportuno sublinhar que em ambos os títulos discutidos neste ensaio, as reflexões relevantes à conjuntura dos dias atuais não só agregam elementos teóricos à compreensão da liquidez e de toda sua volatilidade, evidenciada pelas crises incontáveis que abarcam indivíduos, estruturas e suas relações, mas corroboram a importância do exercício da autocrítica que só a pós-modernidade é capaz de permitir. Dentro deste contexto, o expediente da autoanálise nos é permitido porque "[...] a pós-modernidade é a modernidade que atinge a maioridade, a modernidade olhando-se a distância e não de dentro, fazendo um inventário completo de ganhos e perdas, psicanalisando-se [...]" (BAUMAN, 1999, p. 288). Talvez agora esse exercício seja nosso melhor instrumento contra as alternativas reconfortantes do consumismo, do individualismo e da xenofobia. 


\title{
INSECURITIES, UNCERTAINTIES AND THE POST-MODERN DISAPPOINTMENT: THE STATE OF CRISIS IN THE LAST TEXTS BY ZYGMUNT BAUMAN
}

\begin{abstract}
:
The contemporary social reality is markedly associated with circumstances that generate a "permanent state of crisis". Zygmunt Bauman stood out for the attention devoted to understand the status of crisis in liquid modernity era. This essay sheds light on two of his latest works, namely State of Crisis and Strangers on our doorstep. The arguments and ideas highlighted in the discussion represent possibilities for interdisciplinary approaches that intervene in the human condition and current social practices. In this sense, the loss of State agency power, the diffusion of risks and vulnerabilities, as well as the behavior of estrangement and distrust of otherness, are issues debated in the light of other works by the author and in dialogue with recent contributions of social theory. It concludes by indicating the indissoluble character of the crisis in postmodernity as a source of tension that articulates uncertainties, insecurities and vulnerabilities, stressing individualism and hostility in certain contexts, nevertheless social self-criticism is a possible way to avoid these problems.
\end{abstract}

Keywords: State. Democracy. Migration. Globalization.

\section{INSEGURIDAD, INCERTIDUMBRE Y EL DESÁNIMO POST-MODERN: EL ESTADO DE CRISIS EN LOS ÚLTIMOS TEXTOS DE ZYGMUNT BAUMAN}

\section{Resumen:}

La realidad social contemporánea está marcadamente asociada a circunstancias que generan un "permanente estado de crisis". Zygmunt Bauman se destacó por la atención dedicada a la comprensión del status de crisis en la modernidad líquida. El presente ensayo arroja luz sobre dos de sus últimas obras, a saber, Estado de Crisis y Extraños a nuestra puerta. Los argumentos e ideas destacados para la discusión representan posibilidades de enfoques interdisciplinarios que interpelen la condición humana y las prácticas sociales actuales. En este sentido, la pérdida del poder de agencia del Estado, la difusión de los riesgos y vulnerabilidades resultantes, así como las conductas de extrañamiento y desconfianza a la alteridad, son cuestiones debatidas a la luz de otras obras del autor y en diálogo con contribuciones recientes de la teoría social. La reflexión apunta el carácter indisoluble de la crisis en la posmodernidad como fuente de tensión que articula incertidumbres, inseguridades y vulnerabilidades, aseverando el individualismo y la hostilidad en determinados contextos, siendo la autocrítica social un camino viable para evitar esos problemas.

Palabras clave: Estado. Democracia. Migración. Globalización. 


\section{REFERÊNCIAS}

BAUMAN, Z. O mal-estar da pós-modernidade. Rio de Janeiro: Jorge Zahar Ed., 1998.

BAUMAN, Z. Modernidade e Ambivalência. Rio de Janeiro: Jorge Zahar Ed., 1999.

BAUMAN, Z. Modernidade Líquida. Rio de Janeiro: Jorge Zahar Ed., 2001.

BAUMAN, Z. Comunidade: a busca por segurança no mundo atual. Rio de Janeiro: Jorge Zahar Ed., 2003.

BAUMAN, Z. Identidade: entrevista a Benedetto Vecchi. Rio de Janeiro: Jorge Zahar Ed., 2005.

BAUMAN, Z. Europa: uma aventura inacabada. Rio de Janeiro: Jorge Zahar Ed., 2006.

BAUMAN, Z. Medo Líquido. Rio de Janeiro: Jorge Zahar Ed., 2008.

BAUMAN, Z.; DONSKIS, L. Cegueira moral: a perda da sensibilidade na modernidade líquida. Rio de Janeiro: Jorge Zahar Ed., 2014.

BAUMAN, Z.; BORDONI, C. Estado de Crise. Rio de Janeiro: Jorge Zahar Ed., 2016.

BAUMAN, Z. Estranhos à nossa porta. Rio de Janeiro: Jorge Zahar Ed., 2017.

BECK, U. Sociedade de Risco: rumo a uma outra modernidade. São Paulo: Editora 34, 2010.

CASTELLS, M. A sociedade em Rede. São Paulo: Paz e Terra, 1999.

CROUCH, C. Post-Democracy. Cambridge: Polity, 2004

FAUX, J.; MISHEL, L. Desigualdade e economia global. In: HUTTON, W.; GIDDENS, 
A. No limite da racionalidade: convivendo com o capitalismo global. Rio de Janeiro: Record, 2004, p.137-162.

GIDDENS, A. As consequências da modernidade. São Paulo: Editora Unesp, 1991.

GIDDENS, A. Mundo em descontrole: o que a globalização está fazendo de nós. Rio de Janeiro: Record, 2010.

GIDDENS, A. Continente turbulento e poderoso: qual o futuro da Europa?. São Paulo: Editora Unesp, 2014.

HELD, D.; MCGREW, A. Prós e contras da globalização. Rio de Janeiro: Jorge Zahar Ed., 2001.

SHIVA, V. O mundo no limite. In: HUTTON, W.; GIDDENS, A. No limite da racionalidade: convivendo com o capitalismo global. Rio de Janeiro: Record, 2004, p. 163-186.

STIGLITZ, J. A globalização e seus malefícios: a promessa não cumprida de seus benefícios globais. São Paulo, Editora Futura, 2002.

TOFFLER, A. A terceira onda: a morte do industrialismo e o nascimento de uma nova civilização. Rio de Janeiro: Record, 2001. 